\title{
Acute effect of sacral neuromodulation on video-urodynamic parameters of neurogenic lower urinary tract dysfunction in a patient with vesicoureteral reflux: a case report
}

\author{
Lingfeng Meng ${ }^{1,2 \#}$, Zijian Tian ${ }^{1,2 \#}$, Miao Wang ${ }^{1,2}$, Xiaodong Liu ${ }^{1,2}$, Tianming Ma ${ }^{1,2}$, Jiawen Wang ${ }^{1,2}$, \\ Wei Zhang ${ }^{1,2}$, Yaoguang Zhang ${ }^{1,2}$ \\ ${ }^{1}$ Department of Urology, Beijing Hospital, National Center of Gerontology, Institute of Geriatric Medicine, Chinese Academy of Medical Sciences, \\ Beijing, China; ${ }^{2}$ Beijing Hospital Continence Center, Beijing, China \\ \#These authors contributed equally to this work. \\ Correspondence to: Yaoguang Zhang. No. 1 Dongdan Dahua Road, Dongcheng District, Beijing 100730, China. \\ Email: zhang003887@sina.com.
}

\begin{abstract}
Neurogenic lower urinary tract dysfunction (NLUTD) is a common urological disease that causes long-term complications and severely reduces patient's quality of life. Sacral neuromodulation has proven to be an effective treatment for NLUTD. However, most previous studies have focused mainly on the efficacy and safety of sacral neuromodulation in the treatment of NLUTD and less on the changes in urodynamic parameters in patients before and after sacral neuromodulation. This study aimed to evaluate the effect of short-term sacral neuromodulation on the results of video-urodynamic parameters in a 63-year-old woman with NLUTD with vesicoureteral reflux. The patient was admitted to the Department of Urology of Beijing Hospital in January 2021 and examined using video-urodynamics. In the same month, the patient underwent the first stage of sacral neuromodulation, with an experience period of 2 weeks. After the experience period ended, video-urodynamics was performed again in February 2021. By comparing the two video-urodynamic results, the effect of short-term sacral neuromodulation on the anatomy and physiology of the lower urinary tract was determined. After 2 weeks of sacral neuromodulation treatment, video-urodynamic parameter analysis showed that while the urine storage period of the patient significantly improved, the voiding period was not significantly changed. This was specifically reflected in the improvement of bladder compliance, safe capacity of the bladder, and significant reduction in vesicoureteral reflux. The improvement of the safe capacity of the bladder effectively helped the patient to control the number of intermittent catheterizations within an acceptable range, which greatly improved her quality of life. Therefore, the patient underwent permanent sacral neuromodulation implantation in February 2021. This study suggests that short-term sacral neuromodulation can significantly improve lower urinary tract function and reduce vesicoureteral reflux in patients with NLUTD with vesicoureteral reflux. In short, we believe that sacral neuromodulation may be a good choice for patients with NLUTD.
\end{abstract}

Keywords: Sacral neuromodulation; neurogenic lower urinary tract dysfunction (NLUTD); video-urodynamic; vesicoureteral reflux; case report

Submitted May 05, 2021. Accepted for publication May 19, 2021.

doi: 10.21037/apm-21-1132

View this article at: https://dx.doi.org/10.21037/apm-21-1132 


\section{Introduction}

"Neurogenic bladder" is referred to as lower urinary tract dysfunction caused by nerve injury or nervous system disease (1). Although the terminologies of such diseases have not been unified worldwide, it is recommended to use "neurogenic lower urinary tract dysfunction (NLUTD)" instead of "neurogenic bladder". The term NLUTD was proposed by the International Continence Society (ICS) and is defined as "lower urinary tract dysfunction caused by disorders in the regulation of the nervous system" (2-4). This broad definition provides a more comprehensive summary of different severities of the disease; thus, the term NLUTD was used in this study.

The most common symptoms of NLUTD are dysuria and urinary retention (5). If not treated properly, NLUTD can cause damage even to upper urinary tract function and have a negative effect on patient's life expectancy (6). Therefore, the primary treatment goal is to protect the upper urinary tract function and prevent the occurrence of pyelonephritis, hydronephrosis, and chronic renal failure. The secondary goal is to improve the symptoms of urinary dysfunction to alleviate pain (7).

Current research shows that restoring the lost nerve function through sacral neuromodulation (SNM) is a feasible treatment strategy for NLUTD $(8,9)$. While most previous studies have focused mainly on the efficacy and safety of SNM in the treatment of NLUTD, some focused less on changes in urodynamic parameters in patients with NLUTD before and after SNM.

The ICS recommends urodynamics (UDS) as an important examination method for the diagnosis of lower urinary tract disorders, and it has been widely used (10). Video-urodynamics (VUDS) is based on the traditional UDS examination, combined with real-time image analysis of morphological changes in the lower urinary tract. VUDS can show the anatomical structure and functional status of the bladder and urethra simultaneously. It is currently the most accurate method for diagnosing the pathophysiological changes in the upper and lower urinary tract in patients with NLUTD (11).

Herein, we present the case of a 63-year-old, female NLUTD patient with vesicoureteral reflux (VUR) who was treated with SNM in Beijing Hospital in February 2021, and the changes in VUDS before and after surgery were evaluated. This study aimed to explore the effect of shortterm SNM treatment on the anatomy and function of the lower urinary tract in a patient with NLUTD. We present the following case in accordance with the CARE reporting checklist (available at https://apm.amegroups.com/article/ view/10.21037/apm-21-1132/rc).

\section{Case presentation}

\section{Ethics statements}

All procedures performed in this study were in accordance with the ethical standards of the institutional and/or national research committee(s) and with the Helsinki Declaration (as revised in 2013). Written informed consent was obtained from the patient for publication of this case report and accompanying images. A copy of the written consent is available for review by the editorial office of this journal.

\section{Patient information}

A 63-year-old woman presented with dysuria, urinary incontinence for 4 years, and urinary retention for 1 month. The patient has no other comorbid diseases. In the past, the patient was treated in other hospitals and received treatment such as behavior adjustment and oral drugs, but the effect was poor or ineffective. In January 2021, she was admitted to the outpatient clinic of our hospital and was examined using VUDS (Figure 1A-1C). Before the examination, the patient's residual urine volume after free urination was $160 \mathrm{~mL}$.

\section{UDS evaluation}

UDS evaluation was performed in accordance with the ICS guidelines and by the same doctor $(10,12)$. Before beginning the examination, the patient was instructed to take the lithotomy position for disinfection and catheterization after urination, and the residual urine volume was recorded. The perfusion rate at the time of the examination was $30 \mathrm{~mL} / \mathrm{min}$ and stopped when the patient had a strong desire to urinate or felt uncomfortable. At the end of VUDS, the retractor was connected, pressure measurement catheter was pulled out at a uniform speed of $1 \mathrm{~mm} / \mathrm{s}$, and urethral pressure was recorded.

The following bladder function parameters were recorded: bladder compliance, bladder capacity and pressure when VUR occurs, maximum cystometric capacity, presence or absence of uninhibited detrusor contraction, presence or absence of detrusor contraction and contraction force, maximum urethral pressure, and maximum urethral closure pressure. 


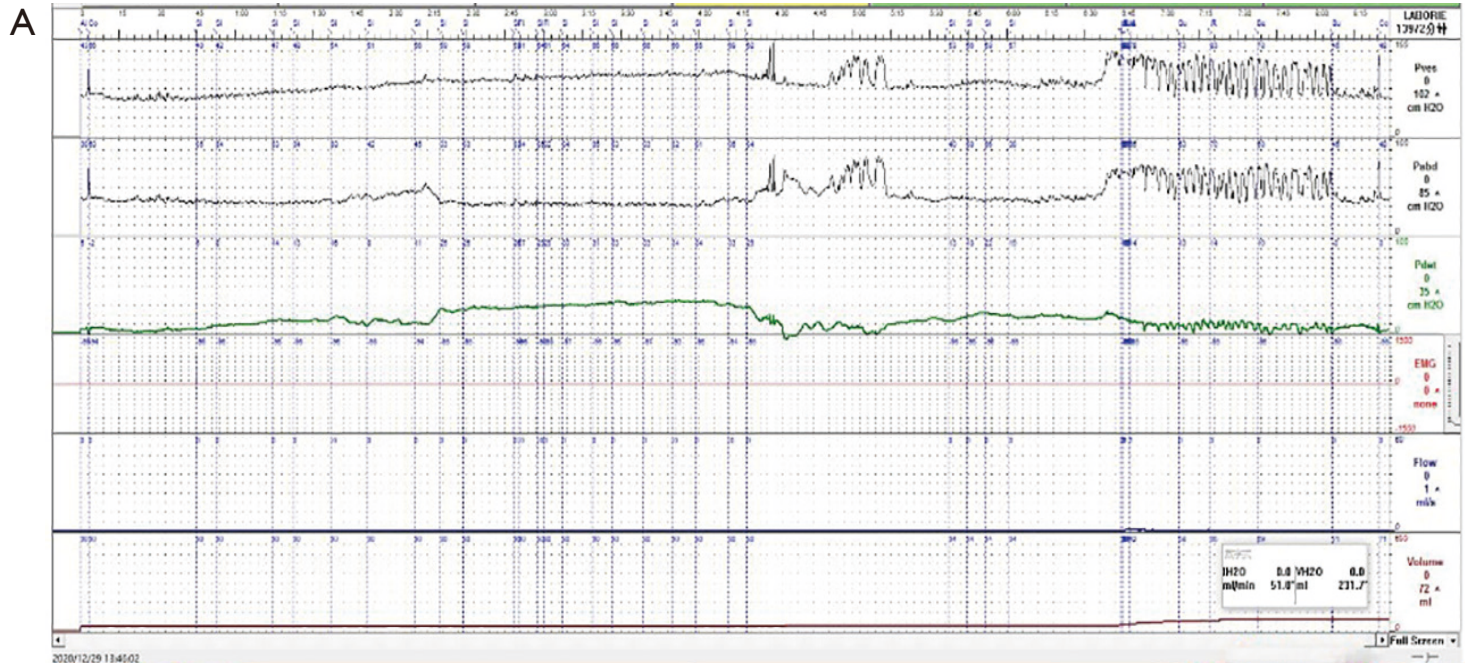

B

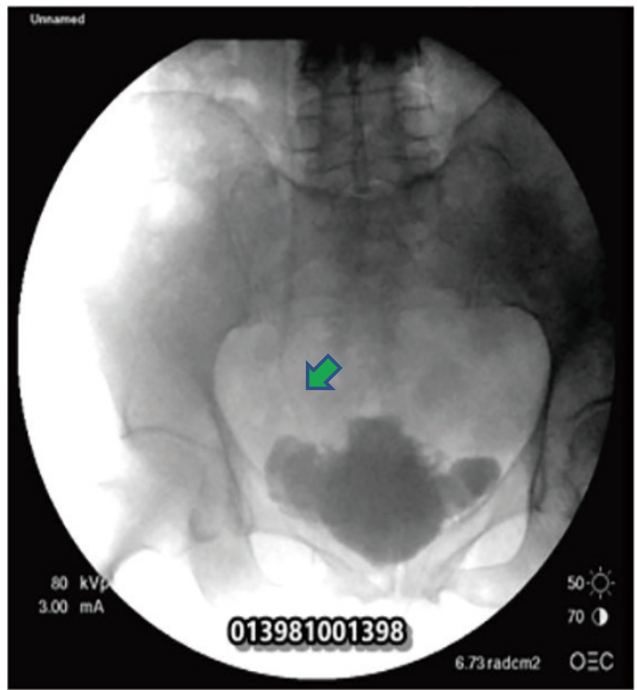

C

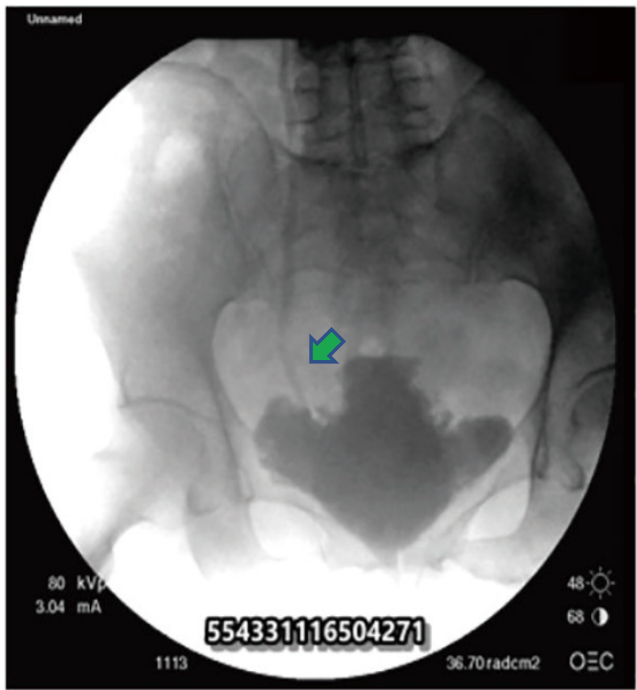

Figure 1 Video-urodynamic results at baseline. (A) The maximum cystometric capacity is $231.7 \mathrm{~mL}$, and the bladder compliance is $4.48 \mathrm{~mL} / \mathrm{cmH}^{2} \mathrm{O}$. (B) Cystography during the filling period shows that VUR began at $90 \mathrm{~mL}$. (C) Cystography during the voiding period shows that the level of right ureteral reflux increased with the increase in abdominal pressure. The arrow shows VUR. VUR, vesicoureteral reflux.

\section{Clinical findings}

The VUDS examination showed that the bladder sensitivity and compliance $\left(4.48 \mathrm{~mL} / \mathrm{cmH}_{2} \mathrm{O}\right)$ decreased during the storage period. Right ureteral reflux began to appear when the bladder pressure was $52 \mathrm{cmH}_{2} \mathrm{O}$ after perfusion to $90 \mathrm{~mL}$ (Figure 1B). There was no active contraction of the detrusor during the voiding period and abdominal pressureassisted micturition, and the maximum change in detrusor contractility compared with the baseline was $14.4 \mathrm{cmH}_{2} \mathrm{O}$. The patient's functional cystometric capacity was $231.7 \mathrm{~mL}$, with first sensation, first desire, and strong desire capacity of 138,146 , and $230 \mathrm{~mL}$, respectively, and the residual urine volume was approximately $110 \mathrm{~mL}$. The patient's maximum urethral pressure was $84 \mathrm{cmH}_{2} \mathrm{O}$, and the maximum urethral closure pressure was $43 \mathrm{cmH}_{2} \mathrm{O}$. On synchronous X-ray images during the filling period, the bladder was abnormal in shape, showing a Christmas-tree shape, and the bladder wall was rough. During the voiding period, the opening of the bladder neck was satisfactory, and the urethra was well visualized. The level of right ureteral reflux increased with an increase in abdominal pressure (Figure 1C). 
A

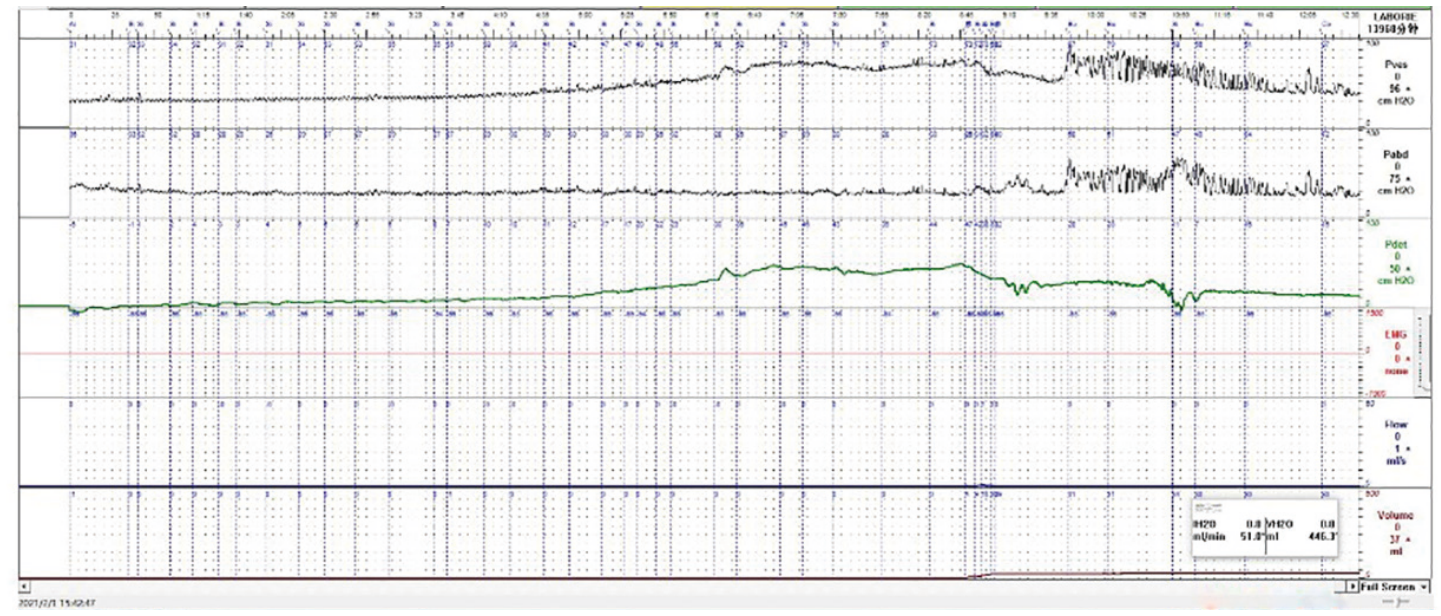

B
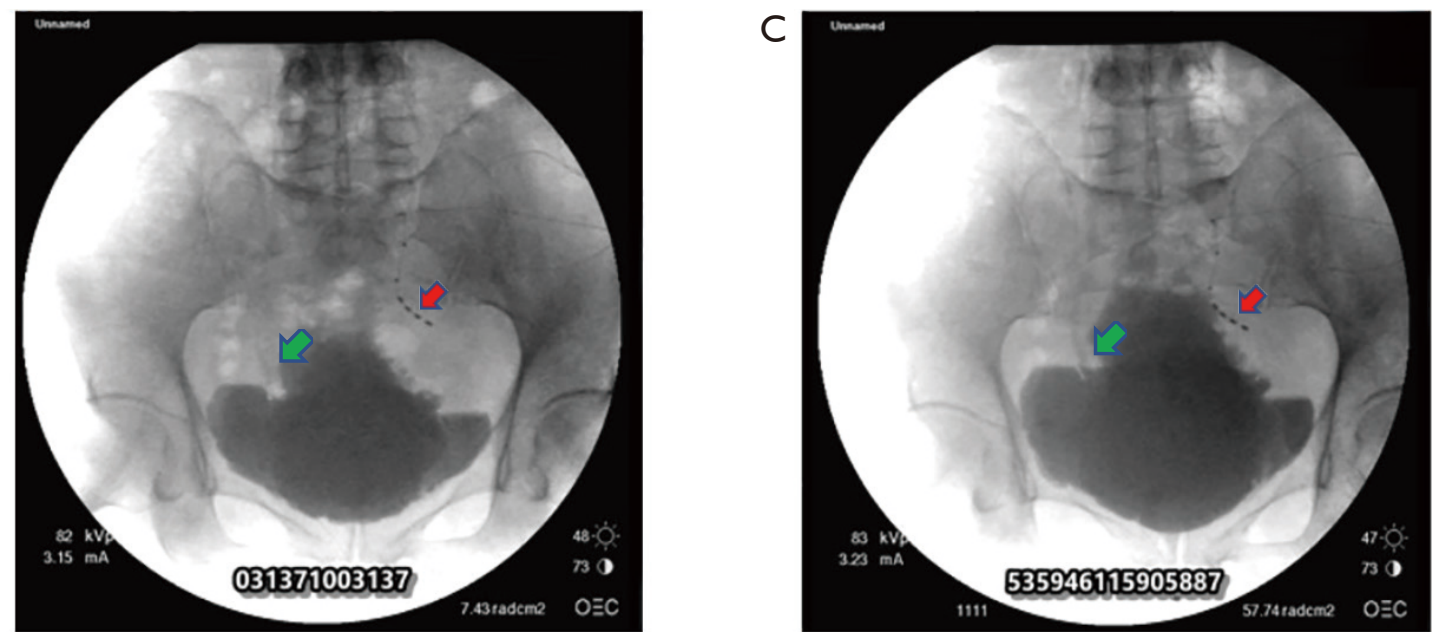

Figure 2 Video-urodynamic results during the testing phase. (A) The maximum cystometric capacity is $446.3 \mathrm{~mL}$, and the bladder compliance is $10.5 \mathrm{~mL} / \mathrm{cmH}_{2} \mathrm{O}$. (B) Cystography during the filling period shows that the VUR began at $340 \mathrm{~mL}$. (C) Cystography during the voiding period shows significant improvement in the reflux volume and level compared with before surgery. The red arrow indicates the tined electrode, and the green one indicates the VUR. VUR, vesicoureteral reflux.

\section{Treatment and outcome}

After reviewing the examination results and obtaining informed consent from the patient, we performed the first stage of SNM on the patient in January 2021. After a 2-week experience period, the VUDS findings were reviewed in the same month (Figure 2A-2C). Before the examination, the patient's residual urine volume after free urination was $380 \mathrm{~mL}$. The VUDS examination showed that bladder compliance was significantly improved during the storage period $\left(10.5 \mathrm{~mL} / \mathrm{cmH}_{2} \mathrm{O}\right)$. When perfused to $340 \mathrm{~mL}$, right ureteral reflux began to occur when the bladder pressure was $72 \mathrm{cmH}_{2} \mathrm{O}$ (Figure $2 \mathrm{~B}$ ). The performance during the voiding period was the same as earlier, and there was no obvious active contraction of the detrusor. The patient's functional cystometric capacity was $446.3 \mathrm{~mL}$, with first sensation, first desire, and strong desire volume of 275,402 , and $413 \mathrm{~mL}$, respectively, and the residual urine volume was about $110 \mathrm{~mL}$. The urethral pressure of the patient was approximately the same as before. Simultaneous X-ray images suggested that with the increase in abdominal pressure, the level of right ureteral reflux also increased (Figure 2C), and the reflux volume and level improved remarkably compared with before the operation. The patient was satisfied with the curative effect and received permanent implantation of SNM (PINS, G132) in February 2021. 


\section{Discussion}

Studies have confirmed that the low bladder compliance in patients with NLUTD not only causes clinical symptoms of frequent urination, urgency, and dysuria but also leads to intravesical hypertension during the filling period and may even impair the upper urinary tract function (13). Therefore, for patients with NLUTD, the golden principle of treatment is to ensure that the detrusor pressure remains within the low-pressure safe range during both the storage and voiding periods, which will significantly reduce the fatality rate due to urinary complications in these patients (14). The European Association of Urology has proposed a more specific treatment goal for patients with NLUTD, that is, to convert an overactive, unstable, high-pressure bladder into a passive, low-pressure, storage allantoic (although it will cause a large amount of residual urine) bladder so that urinary incontinence can be controlled and then to use low-pressure urination methods, such as intermittent catheterization, to empty the bladder (15).

SNM is a new method developed in recent years to treat lower urinary tract dysfunction (including NLUTD), and its effectiveness and safety have been well established (16-19). In addition, a meta-analysis published in 2010 showed that SNM is effective and safe for the treatment of NLUTD (8). However, the analysis included a small number of patients, showed high heterogeneity among studies and lacked support from randomized controlled clinical trials. At the same time, the study did not describe the UDS parameters, so the neurological patient population category that is most suitable for SNM was unclear (8,20-22).

In animal experiments, SNM has been shown to increase bladder capacity and reduce bladder pressure (23). Literature search found that Chaabane et al. began to explore the effects of SNM on the UDS of patients with NLUTD as early as 2011, but they did not make judgments and assessments of the possible combined VUR (24). Therefore, on this basis, Chen et al. retrospectively included 19 patients with NLUTD and evaluated the improvement in SNM during the storage period of patients with NLUTD using VUDS (25). These results suggest that SNM can improve urinary storage function of the bladder in patients with NLUTD to a certain extent. For patients with VUR, SNM can cure or reduce VUR by improving detrusor overactivity and/or bladder compliance.

The conclusion of the present study is similar to that of the study by Chen et al. (25), that is, after receiving SNM treatment, the storage period of the patient was significantly improved, but the voiding period did not significantly improve. Specifically, as reflected in bladder compliance, the safe capacity of the bladder significantly increased and VUR significantly decreased. SNM successfully transformed the patient's small-volume, high-pressure bladder into a largevolume, low-pressure bladder, which reduced the number of intermittent catheterizations and greatly improved her quality of life.

To our knowledge, only one study by Groenendijk et al. presented the acute effects of SNMs on the UDS parameters (26). Specifically, 10 patients with overactive bladder underwent UDS examination before SNM treatment and 1 week after SNM treatment. The results showed no significant difference in the UDS parameters at the two time points, so Groenendijk et al. speculated that the UDS parameters were not affected by short-term SNM. The above conclusions are quite different from those of the present study, because the VUDS parameters of our patient improved to varying degrees or showed a trend of improvement after 2 weeks of SNM. We speculate that there could be two reasons for the different conclusions. First, the patients included in the earlier study were diagnosed with overactive bladder, so the indication of SNM treatment might have been different. Second, in the present study, the duration of SNM treatment was 2 weeks, and the patient had a relatively longer stimulation time to observe improvement in clinical symptoms.

The main limitation of this study is that during the VUDS examination, some of the patient's urine leaked out of the collector, which could not be directly reflected in the examination image. In this case, it can only be calibrated by the examination doctor, which may affect the accuracy of the objective examination results to a certain extent. Another limitation is that we had no follow-up data after SNM permanent implantation as the patient was not due for reexamination by the time this manuscript was communicated.

In conclusion, this study confirmed the satisfactory efficacy of short-term SNM in a patient with NLUTD with VUR; short-term SNM effectively improved lower urinary tract function and reduced VUR. In general, clinicians should have a more positive attitude toward the first stage of SNM implantation in patients with NLUTD.

\section{Acknowledgments}

Funding: This work was supported by the National Key 
R\&D Program of China (2018YFC2002202) and the National Key R\&D Program of China (2016YFC0105505).

\section{Footnote}

Reporting Checklist: The authors have completed the CARE reporting checklist. Available at https://apm.amegroups. com/article/view/10.21037/apm-21-1132/rc

Peer Review File: Available at https://apm.amegroups.com/ article/view/10.21037/apm-21-1132/prf

Conflicts of Interest: All authors have completed the ICMJE uniform disclosure form (available at https://apm. amegroups.com/article/view/10.21037/apm-21-1132/coif). The authors have no conflicts of interest to declare.

Ethical Statement: The authors are accountable for all aspects of the work in ensuring that questions related to the accuracy or integrity of any part of the work are appropriately investigated and resolved. All procedures performed in this study were in accordance with the ethical standards of the institutional and/or national research committee(s) and with the Helsinki Declaration (as revised in 2013). Written informed consent was obtained from the patient for publication of this case report and accompanying images. A copy of the written consent is available for review by the editorial office of this journal.

Open Access Statement: This is an Open Access article distributed in accordance with the Creative Commons Attribution-NonCommercial-NoDerivs 4.0 International License (CC BY-NC-ND 4.0), which permits the noncommercial replication and distribution of the article with the strict proviso that no changes or edits are made and the original work is properly cited (including links to both the formal publication through the relevant DOI and the license). See: https://creativecommons.org/licenses/by-nc-nd/4.0/.

\section{References}

1. Cameron AP. Pharmacologic therapy for the neurogenic bladder. Urol Clin North Am 2010;37:495-506.

2. Gajewski JB, Schurch B, Hamid R, et al. An International Continence Society (ICS) report on the terminology for adult neurogenic lower urinary tract dysfunction (ANLUTD). Neurourol Urodyn 2018;37:1152-61.

3. Gajewski JB, Drake MJ. Neurological lower urinary tract dysfunction essential terminology. Neurourol Urodyn 2018;37:S25-31.

4. Drake MJ, Apostolidis A, Cocci A, et al. Neurogenic lower urinary tract dysfunction: Clinical management recommendations of the Neurologic Incontinence committee of the fifth International Consultation on Incontinence 2013. Neurourol Urodyn 2016;35:657-65.

5. Georgopoulos P, Apostolidis A. Neurogenic voiding dysfunction. Curr Opin Urol 2017;27:300-306.

6. Nseyo U, Santiago-Lastra Y. Long-term complications of the neurogenic bladder. Urol Clin North Am 2017;44:355-66.

7. Kavanagh A, Baverstock R, Campeau L, et al. Canadian Urological Association guideline: Diagnosis, management, and surveillance of neurogenic lower urinary tract dysfunction - Full text. Can Urol Assoc J 2019;13:E157-76.

8. Kessler TM, La Framboise D, Trelle S, et al. Sacral neuromodulation for neurogenic lower urinary tract dysfunction: systematic review and meta-analysis. Eur Urol 2010;58:865-74.

9. Averbeck MA, Moreno-Palacios J, Aparicio A. Is there a role for sacral neuromodulation in patients with neurogenic lower urinary tract dysfunction? Int Braz J Urol 2020;46:891-901.

10. Rosier PFWM, Schaefer W, Lose G, et al. International Continence Society Good Urodynamic Practices and Terms 2016: Urodynamics, uroflowmetry, cystometry, and pressure-flow study. Neurourol Urodyn 2017;36:1243-60.

11. Marks BK, Goldman HB. Videourodynamics: indications and technique. Urol Clin North Am 2014;41:383-91.

12. Lose G, Griffiths D, Hosker G, et al. Standardisation of urethral pressure measurement: report from the Standardisation Sub-Committee of the International Continence Society. Neurourol Urodyn 2002;21:258-60.

13. Vodušek DB. Lower urinary tract and sexual dysfunction in neurological patients. Eur Neurol 2014;72:109-15.

14. Vince RA Jr, Klausner AP. Surveillance strategies for neurogenic lower urinary tract dysfunction. Urol Clin North Am 2017;44:367-75.

15. Stöhrer M, Blok B, Castro-Diaz D, et al. EAU guidelines on neurogenic lower urinary tract dysfunction. Eur Urol 2009;56:81-8.

16. Meng L, Tian Z, Zhang W, et al. Influence of patient sex on the effectiveness of sacral neuromodulation: A cohort study from China. Int J Surg 2020;84:13-7.

17. Meng LF, Zhang W, Wang JY, et al. Clinical outcomes of sacral neuromodulation in non-neurogenic, non- 
obstructive dysuria: A 5-year retrospective, multicentre study in China. World J Clin Cases 2020;8:2494-501.

18. Meng L, Zhang W, Zhang Y, et al. Analysis of the correlation between the clinical effect of sacral neuromodulation and patient age: A retrospective multicenter study in China. Neuromodulation 2020;23:1189-95.

19. Wöllner J, Krebs J, Pannek J. Sacral neuromodulation in patients with neurogenic lower urinary tract dysfunction. Spinal Cord 2016;54:137-40.

20. Lombardi G, Musco S, Celso M, et al. Sacral neuromodulation for neurogenic non-obstructive urinary retention in incomplete spinal cord patients: a tenyear follow-up single-centre experience. Spinal Cord 2014;52:241-5.

21. Puccini F, Bhide A, Elneil S, et al. Sacral neuromodulation: an effective treatment for lower urinary tract symptoms in multiple sclerosis. Int Urogynecol J 2016;27:347-54.

22. Lay AH, Das AK. The role of neuromodulation in patients

Cite this article as: Meng L, Tian Z, Wang M, Liu X, Ma T, Wang J, Zhang W, Zhang Y. Acute effect of sacral neuromodulation on video-urodynamic parameters of neurogenic lower urinary tract dysfunction in a patient with vesicoureteral reflux: a case report. Ann Palliat Med 2022;11(4):1568-1574. doi: 10.21037/apm-21-1132 with neurogenic overactive bladder. Curr Urol Rep 2012;13:343-7.

23. Li X, Liao L, Chen G, et al. Effects of acute sacral neuromodulation at different frequencies on bladder overactivity in pigs. Int Neurourol J 2017;21:102-8.

24. Chaabane W, Guillotreau J, Castel-Lacanal E, et al. Sacral neuromodulation for treating neurogenic bladder dysfunction: clinical and urodynamic study. Neurourol Urodyn 2011;30:547-50.

25. Chen G, Liao L, Wang Y, et al. Urodynamic findings during the filling phase in neurogenic bladder patients with or without vesicoureteral reflux who have undergone sacral neuromodulation. Neurourol Urodyn 2020;39:1410-6.

26. Groenendijk IM, Groen J, Scheepe JR, et al. Acute effect of sacral neuromodulation for treatment of detrusor overactivity on urodynamic parameters. Neurourol Urodyn 2020;39:695-701. 